\title{
Underground Activities and Labour Market Performance
}

Kolm, Ann-Sofie; Larsen, Birthe

Document Version

Accepted author manuscript

Published in:

International Tax and Public Finance

DOI:

10.1007/s10797-018-9505-4

Publication date:

2019

License

Unspecified

Citation for published version (APA):

Kolm, A-S., \& Larsen, B. (2019). Underground Activities and Labour Market Performance. International Tax and Public Finance, 26(1), 41-70. https://doi.org/10.1007/s10797-018-9505-4

Link to publication in CBS Research Portal

\section{General rights}

Copyright and moral rights for the publications made accessible in the public portal are retained by the authors and/or other copyright owners and it is a condition of accessing publications that users recognise and abide by the legal requirements associated with these rights.

Take down policy

If you believe that this document breaches copyright please contact us (research.lib@cbs.dk) providing details, and we will remove access to the work immediately and investigate your claim. 


\title{
Underground Activities and Labour Market Performance
} Ann-Sofie Kolm and Birthe Larsen

\author{
Journal article (Accepted version*)
}

\section{Please cite this article as:}

Kolm, A-S., \& Larsen, B. (2019). Underground Activities and Labour Market Performance. International Tax and Public Finance, 26(1), 41-70. 001: 10.1007/s10797-018-9505-4

This is a post-peer-review, pre-copyedit version of an article published in International Tax and Public Finance.

The final authenticated version is available online at:

DOl: https://doi.org/10.1007/s10797-018-9505-4

* This version of the article has been accepted for publication and undergone full peer review but has not been through the copyediting, typesetting, pagination and proofreading process, which may lead to differences between this version and the publisher's final version AKA Version of Record. 


\title{
Underground activities and labour market performance*
}

\author{
Ann-Sofie Kolm ${ }^{\dagger}$ and Birthe Larsen ${ }^{\ddagger}$
}

4th May 2018

\begin{abstract}
We build a general equilibrium search and matching model with an informal sector. We consider the impact of traditional policy instruments discussed in the tax evasion literature, such as changes in the tax- and punishment system and the employment protection legislation, as well as the impact of concealment costs, on labour market outcomes. The model is calibrated to and simulated on the northern and southern European countries, where countries in the south have significantly higher informal sectors than countries in the north. We conclude that differences in tax- and punishment systems cannot explain the observed difference. Instead, we find that stricter employment protection legislation in southern Europe, as well as the higher tax morale and more extensive use of third-party reporting in northern Europe, are potential candidates for explaining the difference.
\end{abstract}

\section{Introduction}

There is a large interest in combatting work in the informal economy across the industrialised world. There are a number of reasons for that. From a social point of view, informal workers have limited access to social protection and insurance, which may have severe consequences for inequality and poverty in the long run. Moreover, informal work will deprive countries from revenues needed in order to finance the provision of public services, and thus counteracting the very base of a welfare state. In addition, informal work affects labour market outcomes.

The ambition to fight tax evasion in general (and in fact also avoidance) has recently increased. ${ }^{1}$ In 2007, the European Commission started the first EU wide cross national comparable questionnaire to increase the knowledge about tax evasion and undeclared work in Europe in order to combat it (see EC, 2007, 2014). ${ }^{2}$ However, as individuals and firms engaged in the informal economy do not wish to be identified, it is notoriously difficult to collect accurate information about undeclared work. Survey data, such as the Eurobarometer on undeclared work, has been widely used to measure informality. There are, however, limitations with this type of data when the aim is to measure the overall size of the informal economy, or to capture long run effects of policies working through the price channels. General equilibrium effects are simply not likely to be captured using micro level data on individuals or firms of this type.

\footnotetext{
*We want to thank participants at the Shadow 2017 Conference in Warsaw, seminar participants at the School of Economics and Business, Norwegian University of Life Sciences as well as Diana Hornshøj Jensen and Katia Usova for excellent research assistance.

${ }^{\dagger}$ Department of Economics, Stockholm University, SE-106 91 Stockholm, Sweden.

¥Department of Economics, Copenhagen Business School, Porcelænshaven 16A, 2000 Copenhagen F, Denmark, E-mail: bl.eco@cbs.dk, Tel: +4538152798 .

${ }^{1}$ In 2015, the European Commission launched their ambition to step up efforts to combat tax evasion and tax fraud in order to have a more fair and transparent taxation. The Tax Transparency Package presented in 2015 was followed by the Anti Tax Avoidance Package in 2016. Also, the parliament established a European platform to stimulate cooperation in combatting undeclared work (EU 2016). The OECD has also increased their ambition to reduce tax evasion. The OECD initiated the Global Forum of Transparency and Exchange of Information for Tax Purposes in the early 2000s, and it now constitutes the largest tax organisation in the world including both OECD and non-OECD countries (see http://www.oecd.org/tax/transparency/).
}

${ }^{2}$ For the 2007 survey see http://ec.europa.eu/commfrontoffice/publicopinion/archives/ebs/ebs_284_en.pdf. For the 2013 survey see http://ec.europa.eu/commfrontoffice/publicopinion/archives/ebs/ebs_402_en.pdf 
The aim of this paper is instead to capture the equilibrium effects working through the price channels by building a search and matching model with an informal sector. We consider the impact of the traditional policy instruments considered in the tax evasion literature, such as changes in the tax- and punishment system as well as changes in the employment protection legislation, on labour market outcomes. Moreover, we consider the impact of what we refer to as concealment costs of tax evasion. These types of costs reflect that it is difficult, and costly, to hide income from the tax authorities. Such costs have recently gained grounds in the tax evasion literature when it comes to explaining observed tax evasion. The reason is that the traditional policy instruments (employment protection legislation, taxes and punishment policies) have a difficult time explaining the low amount of tax evasion observed. Despite high taxes, stringent employment protection legislation and mild sanctions, we simply observe significantly less tax evasion than what we should expect from traditional theory.

Concealment costs can, for example, capture the use of third-party reporting in an economy. ${ }^{3}$ Also, there is a growing body of literature that stresses the importance of non-economic factors such as morality, guilt and shame as key factors in explaining the puzzle of why tax compliance, after all, is so high. ${ }^{4}$ If there is a strong social norm of tax compliance, it may be socially costly for individuals to evade taxes. These social norms, which in turn can be induced by the institutions and governance structure in the economy, are then proposed candidates for explaining the low amount of tax evasion observed. We also let these types of social costs be captured by the concealment costs.

To analyse the full impact of combatting undeclared work through these policies it will require a general equilibrium framework. The model set-up will allow workers to allocate their search for formal and informal sector jobs optimally. Wages are set in wage negotiations between workers and firms and unemployment features as an equilibrium outcome. To keep the model simple, we account for only a few differences between the formal and the informal sector. The first, and most obvious, difference between the formal and the informal sector is that taxes are paid in the former and a fine is paid upon detection in the latter. Informal sector firms also face concealment costs, which captures that it is costly to hide income from the tax authorities. In addition, formal sector firms will face costs due to employment protection legislation.

We find that increased costs of evasion, either through increased audit rates, more extensive sanctions or thirdparty reporting, or even through policies increasing social costs of evasion, induce a reallocation of firms and workers towards the formal sector. While this is somewhat expected, it is less clear from an a prior point of view, how wages and aggregate unemployment are affected by such policy. We find that informal sector producer wages increase and formal sector producer wages fall, and that more workers are going to find themselves without a job although the formal unemployment rate goes down. Thus, less formal jobs are created than informal jobs being destroyed. This follows as aggregate wage pressure increases.

Increased costs of taxation will instead induce movements towards the informal sector, boosting job creation in the informal sector and reducing the number of workers without a job. Stricter employment protection legislation, will also induce a movement from the formal sector to the informal sector. However, this will not necessarily increase the number of people in a job.

Although the model enables us to analytically pin down how a number of policies and institutional features affect labour market outcomes, it provides no guidence when it comes to the quantitative effects. We know that the size of the informal sector varies widely across countries, and this is so even if we review European countries only. In the World Bank publication on informal work in Europe, it is shown that the Nordic countries have substantially smaller informal sectors than most other countries in Europe. ${ }^{5}$ The largest informal sectors, on the other hand, are

\footnotetext{
${ }^{3}$ See Gordon and Li (2009), Kleven et al. (2011), Kleven (2014), Kleven et al. (2016), Pomeranz (2015), and Bjorneby et al. (2017).

${ }^{4}$ See Andreoni et al. (1998), Perry (2007), and Packard et al. (2012).

${ }^{5}$ See Packard et al. (2012).
} 
found in the countries in southern Europe. ${ }^{6}$ One may then ask which factors are important in explaining the different sizes of the informal sectors across regions. For that reason we calibrate the model to see how important the various policies and institutional featurs considered are in explaining the differences in informal sector activities in northern and southern Europe. We base this numerical exercise on a comparison between four north European countries (Denmark, Finland, Norway, and Sweden) and four south European countries (Greece, Italy, Portugal, and Spain). We use the division of north and south as set out in Hazans (2011), and later used in the World Bank report on informal employment in Europe (see Packard et al. 2012). ${ }^{7}$

We find that taxes and punishment policies affect the size of the informal sector in both northern and southern Europe, but these policy instruments cannot explain the rather large difference in the informal sector shares observed in the two regions. This follows as the taxation of labour, and the probability of being detected and punished doing informal sector work, is not that different between the regions. The slightly stricter employment protection legislation in southern Europe can partly explain why more tax evasion can be observed in southern than in northern Europe. However, concealment costs also need to be lower in southern compared to northern European countries for the model to be able to explain the observed differences in informal sector work between the regions. This is in line with the observed differences in terms of tax administration procedures, where the northern countries make more extensive use of third-party reporting, and also in line with the empirical evidence on tax morale and social costs of tax evasion for the regions.

This numerical exercise also enables us to estimate how many formal sector jobs will be created when informal sector jobs are destroyed since wages will adjust in the long run perspective. We find that a substantial amount of formal sector jobs are created in the long run due to a wage adjustment process, when informal sector jobs are destroyed. Given the simplicity of the model, however, this quantitative exercise should be interpreted with great caution. The results should only be viewed as illustrative in order to shed light on the mechanism for long run outcomes.

Our study relates to the previous literature on tax evasion in a number of ways. ${ }^{8}$ The study, however, is most closely related to the recent strand of literature where issues of tax evasion and undeclared work is addressed in models featuring search and matching frictions. The main bulk of these studies has been on informal sector work from the point of view of low- and middle-income countries. As one can argue that the nature of the informal sector can be quite different in low- and middle income countries compared to high-income countries, the modelling strategies usually differ in their set-ups. As pointed out by la Porta and Shleifer (2014), the informal sector in lowand middle-income countries is usually huge and contains small, unproductive, and stagnant firms. Moreover, the informal sector in this literature is usually seen as an unregulated sector.

Taking a Latin American perspective, Albrecht et al. (2009) account for worker heterogeneity in a search framework, while considering the impact of payroll taxes and severance pay on unemployment in the presence of an informal sector. ${ }^{9}$ The study by Meghir et al. (2015) takes a slightly different modelling approach in its focus on underground activities in Brazil as their paper considers on-the-job-search and firm heterogeneity. Workers may search for jobs both in the formal and the informal sector, and search frictions make it profitable for firms to start

\footnotetext{
${ }^{6}$ This holds in particular for the informal sector measures that capture the type of undeclared work modelled in this paper. Namely workers that, at a given point in time, either work in the formal or the informal sector. Although this is the preferred measure to use according to Packard et al. (2012) when considering available measures for comparisons of the informal sector sizes across countries, it disregards under-declared work (usually referred to as envelope wages). Envelope wages are a phenomenon particularly prevalent in countries in eastern Europe.

${ }^{7}$ Hazans (2011) also include Cyprus and Israel in the group of southern Europan countries. As our calibrations are based on mainly OECD data, Cyprus is left out from our group of southern European countries. Israel is left out as it is not a European country.

${ }^{8}$ The seminal paper by Allingham and Sandmo (1972) and Srinivasan (1973), where under-reporting of income is modelled as a decision made under uncertainty, provides early theoretical analyses of tax evasion. Subsequent papers have since then enhanced the basic model of individual behaviour by, for example, incorporating endogenous labour supply decisions. See for example Sandmo (1981) for an early contribution of endogenous labour supply and underreporting of income. Also equilibrium models with tax evasion have been developed, as, for example, the early study by Cremer and Gahvari (1993) and the studies by Tonin (2011) and Prado (2011).

${ }^{9}$ See also Bosch and Esteban-Pretel (2012) for a model based on a similar set-up calibrated by use of flow data from Brazil. Also Ulyssea (2010) uses Brazilian data to calibrate a search model where firms need intermediate goods from both a formal and an informal sector in their production process of a final good.
} 
both types of jobs. ${ }^{10}$

The literature also includes a number of studies using search and matching set-ups from the perspective of a highincome countries. These studies usually need to assume an asymmetry across the formal and the informal sector in order to generate an informal sector parallel to the formal sector. The study by Kolm and Larsen (2006), for example, explores the consequences of punishment policies on labour market performance in an economy where the underground economy produces different goods as compared to the formal part of the economy. The studies by Fugazza and Jacques (2004) and Kolm and Larsen (2003), on the other hand, explore the consequences for unemployment when workers have moral considerations when deciding on informal sector work. With workers being heterogeneous with respect to moral, only workers with low moral are willing to work in the informal sector. The paper by Boeri and Garibaldi (2002), considers punishment policies in a model of informal employment and involuntary unemployment. However in order to generate co-existence of both formal and informal jobs in their model, all jobs are started as legal jobs. Informal jobs come about as legal firms are hit by a negative productivity shock and face the option of becoming illegal. In contrast, this paper investigates the impact of tax and punishment polices on labour market performance in an equilibrium search and matching model where co-existence of both sectors are not based on any exogenously imposed asymmetry across the two sectors. ${ }^{11}$

The paper is organised as follows. In Section 2 we set up a model including tax and punishment policy as well as concealment costs and employment protection legislation. In the following section, we consider the impact on the informal sector size and unemployment from concealment costs, tax and punishment policy and employment protection legislation. Section 4 provides us with the numerical exercises and the last section concludes.

\section{The Model}

This section considers a two sector general equilibrium model featuring matching frictions and worker-firm wage bargaining. Workers search for jobs both in a formal sector and in an informal sector. Once matched with either a formal or an informal job, there is bargaining over wages. An employed worker is then, at a given point in time, either employed in the formal or the informal sector. This model does not account for the phenomenon of under-declared work (usually referred to as envelope wages). ${ }^{12}$

The formal sector can be taxed whereas the informal sector cannot. Rather than taxing the informal sector, the government audits the economy. With probability $p$ a worker-firm pair in the underground economy is detected and then has to pay a punishment fee. In addition, informal sector activities are associated with costs for concealing the activities. Finally, formal sector firms may face costs related to employment protection, such as firing costs or costs related to providing workers with a safe work environment. For completeness, we include these costs in the model as well.

\subsection{Matching}

The matching function for the formal $(F)$ and the informal $(I)$ sector respectively is given by $X^{j}=\left(v^{j}\right)^{1-\eta}\left(\left(\sigma^{j}\right)^{\gamma} u\right)^{\eta}$, $j=F, I$, where $X^{j}$ is the number of matches, $v^{j}$ is the number of vacancies in the sector, $u$ is the number of unemployed workers, and $\eta$ is a positive parameter, $\eta \in(0,1)$. The unemployed workers allocate their search

\footnotetext{
${ }^{10}$ There are also numerous empirical studies on issues of informality in low- and middle-income countries. See for example Günther and Launov (2012).

${ }^{11}$ There are also papers based on search and matching models considering different aspects of tax evasion than what is done here. For example, while this paper considers workers that at a given point in time, either work in the formal or the informal sector, other studies are concerned with workers being partly employed in the formal sector and partly employed in the informal sector. See Kolm and Nielsen (2008) and Di Nola et al. (2017) for two papers on this issue. Other papers have looked at the impact of tax evasion on other outcomes, such as the impact of tax evasion on educational attainment (Kolm and Larsen, 2016).

${ }^{12}$ Workers being paid cash above their reported wage is an important aspect of informal sector work although not considered in this paper. See Kolm and Nielsen (2008), Williams (2009), and Di Nola et al. (2017) for papers on envelope wages. For policy purpose, however, it may be of importance to study the different types of informal jobs separately. Workers with no attachment to the formal sector may be in a weaker position than workers that only work in the informal sector as a complement to their formal sector job.
} 
effort optimally between the formal and the informal sector. On the job search is disregarded for simplicity. Each worker's total search time is exogenously given and normalised to unity, where $\sigma^{I}=\sigma$ denotes search effort directed towards the informal sector, and $\sigma^{F}=1-\sigma$ denotes search effort directed towards the formal sector. The parameter $\gamma<1$ captures that the effectiveness of search falls with search effort, i.e., the first unit of search in one sector is more effective than the subsequent units of search. This could capture that different search methods are used when searching for a job in a market. The more time that is used in order to search in a market, the less efficient search methods have to be used. This particular modelling strategy of search effort has a close resemblance to how search is modelled in van den Berg and van der Klaauw (2006), where search for a job can be conducted using different search channels.

The transition rates into formal and informal sector employment for a particular worker $i$, are $\lambda_{i}^{F}=\left(1-\sigma_{i}\right)^{\gamma}\left(\theta^{F}\right)^{1-\eta}$ and $\lambda_{i}^{I}=\left(\sigma_{i}\right)^{\gamma}\left(\theta^{I}\right)^{1-\eta}$, where $\theta^{F}=v^{F} /\left((1-\sigma)^{\gamma} u\right)$ and $\theta^{I}=v^{I} /\left(\sigma^{\gamma} u\right)$ are labour market tightness measured in effective search units. As labour market tightness in a sector increases, the transition rate into employment in that sector increases for the individual, i.e., $\lambda_{i}^{j^{\prime}}>0$. The rates at which vacant jobs become filled are $q^{j}=\left(\theta^{j}\right)^{-\eta}, j=F, I$. Higher labour market tightness in a sector reduces the likelihood of firms finding a worker in that sector, i.e., $q^{j^{\prime}}<0$, where $\eta=-\frac{q^{j^{\prime}}}{q^{j}} \theta^{j}, j=F, I$, is the elasticity of the expected duration of a vacancy with respect to tightness.

\subsection{Value functions}

Let $U, E^{F}$, and $E^{I}$ denote the expected present values of unemployment, and employment in the two sectors. ${ }^{13}$ The value functions for worker $i$ then reads:

$$
\begin{gathered}
r U_{i}=R+\lambda_{i}^{F}\left(E^{F}-U_{i}\right)+\lambda_{i}^{I}\left(E^{I}-U_{i}\right), \\
r E_{i}^{F}=R+w_{i}^{F}(1-t)+s\left(U-E_{i}^{F}\right), \\
r E_{i}^{I}=R+w_{i}^{I}(1-p \delta)+s\left(U-E_{i}^{I}\right),
\end{gathered}
$$

where $r$ is the exogenous discount rate, $s$ is the exogenous separation rate, and $w^{j}$ is the sector wage. $R$ is a lump-sum transfer that all individuals receive from the government which reflects that the government has some positive revenue requirements. ${ }^{14}$ The parameter $t$ is the proportional income tax rate, $p$ captures the probability of being detected working in the informal sector, and $\delta$ is the proportion of the evaded income the worker has to pay as a punishment fee if detected.

The unemployed worker $i$ allocates search, $\sigma_{i}$, between the formal and the informal sector in order to maximise the value of unemployment, $r U_{i}$. A necessary condition for an interior solution is that $\gamma<1$, which holds by assumption. The first order condition can be written as:

$$
\frac{\left(1-\sigma_{i}\right)^{1-\gamma}}{\left(\sigma_{i}\right)^{1-\gamma}}=\left(\frac{\theta^{F}}{\theta^{I}}\right)^{1-\eta} \frac{\left(E^{F}-U_{i}\right)}{\left(E^{I}-U_{i}\right)},
$$

where workers allocate their search between the formal and the informal sector so to equalise the net returns to search effort across the two sectors.

Let $J^{F}$ and $V^{F}$ represent the expected present values of an occupied job and a vacant job in the formal sector, respectively. The value functions for a job paying the wage $w_{i}^{F}$ and a vacant job in the formal sector are then

$$
r J_{i}^{F}=y-\mu-w_{i}^{F}(1+z)+s\left(V^{F}-J_{i}^{F}\right),
$$

\footnotetext{
${ }^{13}$ We view all workers not beeing employed as job searchers. Thus we do not consider the impact on labour force participation in the model.

${ }^{14}$ The government cannot exclude the informal sector workers when distributing the transfer as the government does not know who the informal sector workers are (if it did, it could just punish all of them).
} 


$$
r V^{F}=q^{F}\left(J^{F}-V^{F}\right)-k,
$$

where $\mu$ captures costs due to employment protection legislation, $z$ is the payroll tax rate, $y$ is productivity, and vacancy costs are denoted $k$. Analogous notation for the informal sector yields:

$$
\begin{gathered}
r J_{i}=y-w_{i}^{I}(1+p \alpha+\kappa)+s\left(V^{I}-J_{i}^{I}\right), \\
r V^{I}=q^{I}\left(J^{I}-V^{I}\right)-k .
\end{gathered}
$$

The parameter $\alpha$ is the proportion of the evaded wage the firm has to pay as a punishment fee if detected. The concealment cost parameter, $\kappa$, captures that it is costly to evade taxes. The costs could, for example, capture what Kleven et al. (2011) refer to as third-party reporting. When there is third-party reporting of income such as the firm reporting the wage payments directly to the tax authorities, deviations from this have to be agreed upon also by the worker, which is costly. These concealment costs could also be other costs associated with concealing evasion, such as costs due to morality, guilt and shame. These costs are levied on firms in the model, but with qualitatively the same results these costs could equally well be levied on workers. Thus $\kappa$ can be seen as capturing the firm's and the workers's concealment costs of evasion.

\subsection{Wage Determination}

When a worker meets either a firm offering a formal sector job or a firm offering a job in the informal sector, they bargain over the wage, $w_{i}^{j}$, taking economy wide variables as given. With symmetric bargaining between the worker and firm, the first order conditions from the Nash bargaining solutions are:

$$
\begin{gathered}
\frac{1}{\phi^{F}} J_{i}^{F}=E_{i}^{F}-U, \\
\frac{1}{\phi^{I}} J_{i}^{I}=E_{i}^{I}-U,
\end{gathered}
$$

where $\phi^{F}=\frac{1+z}{1-t}$ and $\phi^{I}=\frac{1+p \alpha+\kappa}{1-p \delta}$ are the tax and punishment wedges, when we have imposed symmetry within each sector and the free entry condition, $V^{j}=0, j=F, I$. We can now derive an equation determining how search is allocated between the two sectors in equilibrium by substituting (9) and (10) into (4) and using that $J^{F}=k / q^{F}$ and $J^{I}=k / q^{I}$ from (6) and (8) together with free entry. This yields the following core equation:

$$
\frac{(1-\sigma)^{1-\gamma}}{(\sigma)^{1-\gamma}}=\frac{\theta^{F}}{\theta^{I}} \psi
$$

where $\psi=\phi^{I} / \phi^{F}=\frac{1+p \alpha+\kappa}{1-p \delta} / \frac{1+z}{1-t}$ is the wedge between the informal sector and the formal sector. We can interpret a $\psi>1$ as the case when it is more costly in terms of expected punishment and concealment costs in the informal sector relative to the cost of taxation in the formal sector. This case is in line with the results found in Kleven et al. (2011) where it was shown that concealment costs are likely to be very high due to third-party reporting in high-income countries, indicating that $\psi>1$. This case is also in line with the growing body of literature pointing towards the importance of non-economic factors, such as costs due to morality, guilt and shame, explaining the rather high tax compliance despite high tax rates, low audit rates, and fairly modest fines.

When workers allocate their search between the formal and the informal sector in equilibrium, they account for the wedge, $\psi$, and for the formal relative to the informal sector tightness, $\theta^{F} / \theta^{I}$. More specifically, relatively more search will be directed towards the formal sector if expected punishment plus concealment costs are higher than the tax rates, i.e. if $\psi>1$, and/or if formal sector tightness exceeds informal sector tightness, i.e., $\theta^{F} / \theta^{I}>1$. And vice versa when $\psi<1$ and $\theta^{F} / \theta^{I}<1$.

By use of equation (1)-(8) and (11) in equations (9) and (10), equilibrium producer wages, $\omega^{j}, j=F, I$, are given by: 


$$
\begin{gathered}
\omega^{F}=w^{F}(1+z)=\frac{1}{2}\left((y-\mu)+\frac{k \theta^{F}}{(1-\sigma)^{1-\gamma}}\right), \\
\omega^{I}=w^{I}(1+p \alpha+\kappa)=\frac{1}{2}\left(y+\frac{k \theta^{I}}{\sigma^{1-\gamma}}\right) .
\end{gathered}
$$

Wages increase with labour market tightness and decrease with search intensity in each sector. This follows as a higher labour market tightness and a lower search intensity improve the worker's bargaining position. An increase in tightness makes it easier for a worker to find a job in case of job loss, and at the same time harder for a firm to fill a vacancy. This improves the worker's relative bargaining position, resulting in higher wage demands. The opposite holds when search increases as then firms will find it relatively easier to match with a new worker in case of no agreement. Higher search effort into a sector then reduces the worker's relative bargaining position, resulting in lower wage demands.

\section{Informal Sector Size and Unemployment}

The employment rates for workers in the formal sector and the informal sector, $n^{F}, n^{I}$, and the actual unemployment rate, $u$, are determined by the flow equilibrium, $\lambda^{j} u=s n^{J}, j=F, I$, and the labour force identity, $n^{F}+n^{I}=1-u$. The official unemployment rate, $u^{o}$, is given by $u^{o}=u+n^{I}$. Solving for the employment and unemployment rates yield:

$$
n^{j}=\frac{\lambda^{j}}{s+\lambda^{I}+\lambda^{F}}, j=F, I, u=\frac{s}{s+\lambda^{I}+\lambda^{F}}, u^{o}=\frac{s+\lambda^{I}}{s+\lambda^{I}+\lambda^{F}} .
$$

Note that as official unemployment includes the informal sector workers too, an increase in the transition rate into the informal sector increases the official unemployment rate, whereas the actual unemployment rate falls. The share of informal employment, $\rho$, will then be given by

$$
\rho=\frac{n^{I}}{n^{F}+n^{I}}=\frac{\lambda^{I}}{\lambda^{F}+\lambda^{I}}
$$

As the transition rates, $\lambda^{F}=(1-\sigma)^{\gamma}\left(\theta^{F}\right)^{1-\eta}$ and $\lambda^{I}=\sigma^{\gamma}\left(\theta^{I}\right)^{1-\eta}$, are pinned down by labour market tightness in the sectors and search intensity, deriving search intensity, $\sigma$, formal sector labour market tightness, $\theta^{F}$ and informal sector labour market tightness, $\theta^{I}$, are then key for determining the size of the informal sector and the actual and official unemployment in the economy. Using equations (5), (6), (7) and (8), free entry and then inserting for wages from equation (12) and (13), we have the equations determining labour market tightness in the formal and the informal sector. These equations and the search equation in (11), repeated below, give three equations determining search intensity, $\sigma$, formal sector labour market tightness, $\theta^{F}$ and informal sector labour market tightness, $\theta^{I}$ :

$$
\begin{gathered}
\frac{(1-\sigma)^{1-\gamma}}{\sigma^{1-\gamma}}=\frac{\theta^{F}}{\theta^{I}} \psi, \\
2(r+s) k\left(\theta^{F}\right)^{\eta}=(y-\mu)-\frac{k \theta^{F}}{(1-\sigma)^{1-\gamma}} \\
2(r+s) k\left(\theta^{I}\right)^{\eta}=y-\frac{\psi k \theta^{F}}{(1-\sigma)^{1-\gamma}}
\end{gathered}
$$

As is clear from equations (16)-(18), important determinants are the wedge, $\psi$, and costs of employment protection legislation, $\mu$. 
Recall, that the wedge between the informal sector and the formal sector is given by

$$
\psi=\phi^{I} / \phi^{F}=\frac{1+p \alpha+\kappa}{1-p \delta} / \frac{1+z}{1-t}
$$

The wedge between the informal and formal sector has several components. The tax system will clearly have an influence on the wedge as will the audit and punishment rates. The other important component in the wedge is the concealment costs, denoted by $\kappa$. Next, in turn, we will discuss the impact of the different factors affecting unemployment and the size of the informal sector derived from the model. We will also discuss the expected effect of these factors based on the previous literature.

\subsection{Concealment Costs}

The concealment costs, $\kappa$, capture that it is costly to hide income from the tax authorities. This component has recently gained grounds in the tax evasion literature when in comes to explaining the low level of observed tax evasion. The reason is that the traditional policy instruments (employment protection legislation, taxes, and punishment policies), have a difficult time explaining the observed tax evasion. Despite high taxes, stringent employment protection legislation and mild sanctions, we simply tend to observe significantly less tax evasion than what we should expect.

High concealment costs can, for example, be due to extensive use of third-party reporting. Also, there is a growing body of literature that stresses the importance of non-economic factors such as morality, guilt and shame as key factors in explaining the puzzle of why tax compliance, after all, is so high despite high taxes and low audit and punishment rates (see Andreoni et al. 1998, Perry 2007, and Packard et al. 2012).

It is easy to understand that an extensive system of third-party reporting makes it difficult, and thus costly, for firms and workers to evade taxes. For example, employers withholding taxes at the source, and reporting the income of their employees directly to the tax authorities, makes it difficult for employees to under-report income and evade taxes. And vice versa, it will be difficult for the firm to deviate from what is reported to the tax authorities when it pays out the wage income to an employee, unless the employee is in agreement with the employer. Thus, to evade taxes, the firm and the worker need to collude on a non-compliance behaviour.

There is a wide support in the literature, both theoretical and empirical, for that the presence of third-party reporting induces strong incentives for tax compliance, whereas the opposite holds when there is no third-party reporting in place. For example, Kleven at al (2016) develops a theoretical model where employees are potential whistleblowers, explaining the importance of third-party reporting for tax compliance. ${ }^{15}$ See also Kleven et al. (2011) and Pomeranz (2015) for two studies making use of field experiments to identify the importance of third-party reporting for tax compliance and evasion.

Non-economic factors such as social costs of evasion can also play an important role explaining the low amount of tax evasion observed. If there is a strong social norm of tax compliance, it may be socially costly for individuals to evade taxes, which would be reflected in a high $\kappa$ and limited evasion. Social norms, which in turn are induced by the institutions and the governance structure in an economy, is then a proposed candidate for explaining why we observe less tax evasion in the economy than what is expected from traditional theory.

Empirical evidence indicates that there is an inverse relationship between the size of the informal economy and tax morale in an economy (see Packard et al. 2012). Based on a review of the empirical literature, Torgler (2011a) presents characteristics of institutions and the governance structures that tend to increase tax moral in an economy. More specifically, he stresses the government's effectiveness, control of corruption, rule of law, and regulatory quality, as being important factors for tax morale. An efficient government with no, or limited, corruption

\footnotetext{
${ }^{15}$ They provide an explanation for why development may reduce tax evasion as development is often associated with employment growth, and thus more whistleblowers.
} 
increases the trust for the authorities and improves the incentives to cooperate and contribute to the economy. Tax compliance then increases. ${ }^{16}$ Moreover, Frey and Torgler (2007) explicitly explore the importance of trust between tax payers and the state and the impact it has on tax compliance. They find that a one unit increase in their trust measure for the justice system increases the population who reports the highest tax moral by more than three percentage points.

In our model, the parameter $\kappa$ captures concealment costs of all these types, and the effect of an increase in $\kappa$ is derived in the following proposition:

Proposition 1. Higher concealment costs, $\kappa$, will induce workers to reallocate search intensity towards the formal sector ( $\sigma$ falls). Furthermore, it will increase tightness and employment in the formal sector $\left(\theta^{F}, n^{F}\right)$ and reduce tightness and employment in the informal sector $\left(\theta^{I}, n^{I}\right)$. The share of informal sector employment, $\rho$, therefore falls and official unemployment, $u^{o}$, falls.

When underground activities are more difficult, and thus more costly, to conceal, for example due to third-party reporting or social norms, unemployed workers will find it optimal to reallocate their search effort towards the formal sector. However, when search intensity is reallocated towards the formal sector, wage pressure in the formal sector falls whereas wage pressure in the informal sector increases. Workers' increased search for formal sector jobs reduce the workers' relative bargaining position which restrains formal wage demands. In contrast, the reduced search in the informal sector strengthens workers' relative bargaining position in the informal sector inducing informal wages to increase. Firms will find it relatively more profitable to open formal sector jobs, leading to an increase in formal sector employment at the expense of informal sector jobs.

The fact that the informal sector is reduced when it becomes more costly to evade taxes is not surprising. The formal sector will, on the other hand, increase in size, and the model provides the mechanisms where wage adjustments turn out to play a key role for long run effects. Thus, formal sector jobs will to some extent replace forgone jobs in the informal sector in a long run general equilibrium setting. The question is, however, to what extent formal sector jobs are created as informal sector jobs are destroyed. The results depend on the size of the wedge in relation to employment protection legislation:

Proposition 2. The impact of higher concealment costs, $\kappa$, on actual unemployment depends on employment protection legislation $\mu$ and the informal sector wedge $\psi$. In the absence of employment protection legislation, $\mu=0$, higher concealment costs, $\kappa$ will decrease actual unemployment, ( $u$ falls), if $\psi<1$ and increase unemployment if $\psi>1$ ( $u$ increases). In the presence of employment protection legislation, $\mu>0$, then there exists a $\psi^{*}>1$ where unemployment falls (increases) with $\kappa$ for $\psi<(>) \psi^{*}$.

In an economy with no employment protection legislation for the formal sector workers, then actual unemployment increases (decreases) when it becomes more costly to be informal if $\psi>(<) 1$. The case when it is more costly in terms of expected punishment and concealment costs in the informal sector relative to the cost of taxation in the formal sector, i.e., $\psi>1$, is consistent with higher tax compliance than non-compliance. This is the most realistic case to consider for high income countries where the informal sector is observed to be smaller than the formal sector. In this case, the large concealment costs discourage workers from searching, and firms from

\footnotetext{
${ }^{16}$ See Packard et al. (2012) for a discussion.
} 
opening vacancies, in the informal sector. In fact, too few firms and too little search are allocated into the informal sector from an efficiency point of view. Increased punishment of the informal sector will encourage further reallocation of search and workers away from the informal sector, where relatively efficient search methods are used, towards the formal sector. Total search efficiency then falls, inducing unemployment to increase. The fact that search becomes less efficient when reallocated towards the formal sector also has an impact on unemployment working through wage formation and tightness. As search is reallocated towards the formal sector, the wage demand is moderated in the formal sector and exaggerated in the informal sector. As the efficiency of search in the formal sector increases by less than the efficiency of search in the informal sector is reduced, the informal sector wage push will dominate the formal sector wage moderation. Thus, the incentives to open up a vacancy in the formal sector sub-seeds the disincentives to open up a vacancy in the informal sector; formal sector tightness will increase by less than informal sector tightness falls when $\psi>1$. Hence, although destruction of informal sector jobs stimulates formal sector job openings in equilibrium, formal sector jobs will not be opened to the same extent as informal jobs are destroyed; actual unemployment increases.

The opposite holds if $\psi<1$. In this case too much search, and too many firms, are allocated into the informal sector as there is a relative cost advantage of producing underground. Total search efficiency would then improve, and aggregate wage pressue fall, when the government tries to combat the informal sector.

In the presence of employment protection legislation, $\mu>0$, the informal sector becomes relatively more attractive and more search will be directed towards the informal sector than is the case when $\mu=0$. Therefore even for a wedge larger than unity, actual unemployment will fall until labour market tightness in the formal sector is equal to labour market tightness in the informal sector and $\sigma$ is equal to a half, that is, when $\psi=\psi^{*}>1$.

The results in proposition 2 capture how formal sector jobs are replacing informal sector jobs through general equilibrium effects. To account for the effects working through wage adjustments turns out to be key when deriving the long run effects. There are no empirical studies considering this issue, due to the implied extensive challenges with respect to data. However, considering the importance of the research question, the model serves as a guideline for the potential mechanism that this process works through. Section 4 takes the model to data in order to provide a rough estimate of how many formal sector jobs are created when informal sector jobs are destroyed.

\subsection{Tax and punishment policies}

It is clear that taxes are crucial for the size of the informal sector. In fact, in absence of taxes the informal sector by definition may not exist. ${ }^{17}$ The impact of taxes and enforcement policies has also been investigated in a number of theoretical and empirical studies. According to theory, higher taxes and lower enforcement, induce more tax evasion. See, for example, the seminal paper by Allingham and Sandmo (1972) where individual tax evasion was modelled as a decision made under uncertainty. There is also evidence that taxes play an important role, not only in theory, when explaining workers' and firms' decision to engage in informal activities. According to the Eurobarometer survey (EC 2007, 2014), where individuals are asked to report undeclared work, taxes are stressed as an important factor for choosing to work informally. Also, surveys directed to firms suggest that high taxes are obstacles for firms in the formal sector (see World Bank enterprise surveys).

In our model, a higher expected punishment of the informal sector relative to taxes, that is higher $p \alpha$ or $p \delta$ relative to $z$ or $t$, increases the wedge $\psi$ and therefore has the following impact on the economy:

\footnotetext{
${ }^{17}$ This holds for many definitions of informal activities such as activities that are legal but are not declared to tax authorities or social security institutions (EC, 2007, Højsgaard et al. 2017). However, other definitions imply that there could be an informal sector although no taxes need to be paid. For example definitions based on activities carried out without following the employment protection legislation.
} 
Proposition 3. Higher expected punishment of the informal sector relative to taxation, i.e., a higher p $\alpha$ or $p \delta$ relative to $\phi^{F}$, which increases the wedge $\psi$, will induce workers to reallocate search intensity towards the formal sector ( $\sigma$ falls). Furthermore, it will increase tightness and employment in the formal sector $\left(\theta^{F}, n^{F}\right)$ and reduce tightness and employment in the informal sector $\left(\theta^{I}, n^{I}\right)$. The share of informal sector employment, $\rho$, therefore falls and official unemployment, $u^{0}$, falls.

In addition, the impact on actual unemployment, which depends on the size of the wedge in relation to the employment protection legislation, is presented here:

Proposition 4. The impact of higher expected punishment of the informal sector relative to taxation, i.e., a higher p $\alpha$ or $p \delta$ relative to $\phi^{F}$, which increases the wedge $\psi$, on actual employment depends on employment protection legislation, $\mu$, and the wedge, $\psi$. In the absence of employment protection legislation, $\mu=0$, then higher $p \alpha, p \delta$ or lower $\phi^{F}$, will decrease actual unemployment ( $u$ falls) if $\psi<1$ and increase unemployment ( $u$ increases) if $\psi>1$. In the presence of employment protection legislation, $\mu>0$, then there exists $a \psi^{*}>1$ where unemployment falls (increases) with higher $p \alpha, p \delta$ or lower $\phi^{F}$ for $\psi<(>) \psi^{*}$.

When the informal sector experiences more extensive punishment or taxation is reduced, the informal sector wedge, $\psi$, increases. Workers will find it optimal to reallocate their search effort towards the formal sector and official unemployment falls. Actual unemployment increases if we have a situation where compliance is higher than non-compliance; i.e, $\psi$ is large enough $\left(\psi>1\right.$ when $\mu=0$, and $\psi>\psi^{*}>1$ when $\left.\mu>0\right)$, and vice versa if $\psi$ is low enough $\left(\psi<1\right.$ when $\mu=0$, and $\psi<\psi^{*}>1$ when $\left.\mu>0\right)$. These policy instruments (taxes and punishment policies) clearly have a similar impact on the size of the informal sector and the official and actual unemployment, as a more structured administrative process of third-party reporting, or social norms, which we considered above.

\subsection{Employment protection legislation}

Employment protection legislation is in the literature put forth as an important factor explaining informal activities. A stricter employment protection legislation simply increases the costs for formal sector firms but not so for informal sector firms, which increases the incentives to engage in informal activities. Empirical cross country comparisons unambiguously support this hypothesis. ${ }^{18}$

The impact of stricter employment protection legislation in our model is captured by $\mu$. As the formal sector faces employment protection legislation, this per se, tends to reduce labour market tightness in the formal sector relatively to in the informal sector. Hence even for $\psi=1$ we have that the informal sector labour market tightness exceeds formal sector tightness. Thus, when considering the symmetric case, we need the wedge to be larger than one, $\psi>1$, in order to obtain that formal sector tightness is higher than informal sector tightness. The impact on the equilibrium from more employment protection is given by the following proposition.

Proposition 5. A higher employment protection legislation, $\mu$, will reduce formal sector labour market tightness and employment, $\left(\theta^{F}, n^{F}\right)$, and increase informal sector labour market tightness and employment, $\left(\theta^{I}, n^{I}\right)$. Search into the informal

\footnotetext{
${ }^{18}$ See Fialova and Schneider (2011) and Hazans (2011).
} 
sector, $\sigma$, increases and official unemployment, $u^{0}$, increases. The share of informal sector employment increases, that is, $\rho$ increases.

When formal sector firms face employment protection legislation, jobs are more costly and fewer formal sector jobs are supplied. Unemployed workers will find it optimal to reallocate their search effort towards the informal sector. However, when search is reallocated towards the informal sector, wage pressure in the informal sector falls whereas wage pressure in the formal sector increases. Workers' increased search for informal sector jobs reduces the workers' relative bargaining position which restrains informal wage demands. In contrast, the reduced search in the formal sector strengthens workers' relative bargaining position in the formal sector inducing formal wages to increase. Firms will find it even more profitable to open informal sector jobs, leading to an increase in the informal sector relative to the formal sector. Official unemployment increases and the share of informal employment increases. The impact on actual unemployment is ambiguous.

\section{Numerical Exercises}

The size of the informal sector varies widely across countries, and this is so even if we consider a European context only. In the World Bank publication on informal work in Europe, it is shown that the Nordic countries have substantially smaller informal sectors than most other countries in Europe. ${ }^{19}$ The largest informal sectors, on the other hand, are found for countries in Southern Europe. This holds in particular for the informal sector measures that capture the type of undeclared work modelled in this paper. Namely workers that, at a given point in time, either work in the formal or the informal sector. ${ }^{20}$

Based on the observed country differences in the sizes of the informal sectors, we ask which factors are important for explaining them. For that reason, we calibrate the model to see how important the various policies and institutional features considered here are in explaining the differences in informal sector activities in northern and southern Europe. We base this numerical exercises on a comparison between four north European countries (Denmark, Finland, Norway, and Sweden) and four south European countries (Greece, Italy, Portugal, and Spain). These two groups will from now on be referred to as North and South. We use the division of North and South as set out in Hazans (2011), and later used in the World Bank report on informal employment in Europe (Packard et al. 2012), except for that they include Cyprus and Israel in the group South additionally. We choose to exclude Israel in our comparison in order to focus on only European countries, and Cyprus is excluded because we base our calibrations mainly on OECD data.

The literature has estimated the size of the informal sector in different countries using various methods. A commonly used cross country comparison estimation of the informal sector size is presented in a series of papers by Schneider (see Schneider et al. 2010 and Buehn and Schneider, 2012). These estimates are based on the MIMIC technique (multiple inputs multiple causes estimation), where instead of using a method where a single factor or indicator can capture all activities in the informal sector, such as the currency demand approach or the electricity approach, they estimate the size using a method which includes multiple indicators of the informal sector. These estimates measure the extent of informality in relation to GDP and the estimates are rather sizeable. ${ }^{21}$

\footnotetext{
${ }^{19}$ See Packard et al. (2012).

${ }^{20}$ Countries in central and eastern Europe also have fairly large informal sectors. However, the undeclared work in these countries seems to a larger extent be derived from under-declared work (usually referred to as envelope wages). See Packard et al. (2012) and Hazans (2011). This type of informal employment is not captured in our model or in the measure of informal sector employment we are using in this section.

${ }^{21}$ See Feige (2016) for a paper discussing problems with these estimates of the informal sector.
} 
This paper will instead use the cross country estimations of the informal sector size presented in Hazans (2011). These measures capture the size of the informal sector in terms of the informal sector employment shares across countries. More specifically, we will use the estimates of the share of informal employees out of all employees, which is a measure that very closely corresponds to the variable derived in our model. The cross country estimates in Hazans (2011) are derived using data from the European Social Survey (ESS) and focus on dependent workers without contracts. ${ }^{22}$

Looking at the measures of the size of the informal sector, it is clear that informality is substantially more prevalent in South than in North. According to the estimates, the proportion of employees without a contract among all employees in 2008/2009 varies from 3 percent in North to 13.6 percent in South. ${ }^{23}$

In terms of official unemployment rates, North performs better than South. The average unemployment rate over the period 2006-2016 for workers in the age group 15-64 has been 6.2 percent in North and 14.2 percent in South. Considering taxation there are only marginal differences between the groups. According to data from the OECD, the average general government expenditures over the period of 2006-2015 was 51 percent of GDP for the four countries in North and 49 percent for the four countries in South.

Calculations of the tax wedge on wage income $(1+z) /(1-t)$ using OECD data draws a similar pattern for the two regions. More specifically, over the period 2006-2016, the tax wedge on wage income was 1.68 in North and 1.73 in South, thus indicating a slightly higher effective tax wedge in South than in North. ${ }^{24}$

To get accurate numbers for the punishment policies, in terms of audit rates and punishment fees, is substantially more complicated. Such figures are simply not easily available in comparable cross country data sets. It is, however, evident that the effective expected punishment fees, $p \alpha$ and $p \delta$, are very low in most countries. According to Packard et al. (2012) the observed punishment fees are typically modest and seldom exceed more than the amount of unpaid taxes. This corresponds to setting $\alpha=z$ and $\delta=t$ capture an upper bound on the punishment fees in our model, where $\mathrm{z}$ and $\mathrm{t}$ clearly are smaller than unity in non-confiscatory tax systems. Moreover, the percentage of individual income tax returns that are subject to a thorough tax audit is typically less than one percent of all returns according to Packard et al. (2012). This corresponds to an audit rate of less than $p=0.01$, which implies that $p \alpha$ and $p \delta$ are extremely small. As the expected punishment rates are very small both in North and South, and there is no specific cross country evidence arguing for larger or smaller rates in North than in South, we will not differentiate across North and South with respect to expected punishment rates in the numerical exercises.

To get accurate numbers for concealments costs in terms of $\mathcal{K}$ for the two regions is tricky as the variable captures a number of different things, and on top of that, these things are usually difficult to measure. The concealment costs could capture the cost of evasion due to third-party reporting, but also costs due to morality, guilt, and shame.

Although the research literature provides strong support third-party reporting effectively reduces tax evasion and increases tax compliance, there are no readily available cross country estimates on the degree of third-party reporting in our two regions. The evidence, however, shows that third-party reporting processes are more developed in North than in South.

To find an estimate on the degree of third-party reporting in the South and North, we make use of the OECD tax administration report on third-party reporting published in 2008 (OECD, 2008). The report focuses on the progress

\footnotetext{
${ }^{22}$ See Packard et al. (2012) for a discussion of the three most commonly used methods of how to define an informal employee; firm size criterion, social contribution criterion, and contract criterion. The contract criterion is considered the preferred proxy for measuring informal employees based on reliability when it comes to comparisons across countries, and the fact that it is less ambiguous and significantly more observable than the other criterions.

${ }^{23}$ The measure derived for Italy stems from 2006, whereas the rest of the countries derive from 2008/2009. Excluding Italy will increase the difference in the size of the informal sector between the regions, as will including Israel and Cyprus in accordance with the division between South and North in Hazans (2011).

${ }^{24}$ The OECD calculates country specific measures for a tax wedge by calculating the combined central and sub-central government income taxes paid plus the employee and employer social security contribution taxes paid as a share of labour costs defined as gross wage earnings plus employer social security contributions. In our model this corresponds to the following measure: $T W=(z+t) /(1+z)$ where $T W$ denotes the OECD wedge. Using this measure, we can derive the measure for the tax wedge presented in section 2.3 as $(1+z) /(1-t)=1 /(1-T W)$. See http://stats.oecd.org/index.aspx?DataSetCode=TABLE_I5
} 
of third-party reporting in Denmark and Sweden, as these countries have served as role models when it comes to third-party reporting and, because of that, the implementation of pre-filled personal tax returns. Despite the focus on Denmark and Sweden, the report also provides information about the latest known developments regarding implementation of pre-filled personal tax returns that builds on third-party reporting in other countries. By using the amount of years these procedures were implemented prior to 2009 for each country in our two regions, we can calculate the average number of years the pre-filled personal tax return systems based on third-party reporting has been operating. In North the average number of years these procedures have been in place is 15 years, whereas South has had these systems in place for two years on average.

As was discussed in section 3, there is a growing body of literature that stresses the importance of non-economic factors such as morality, guilt and shame as key factors in explaining the puzzle of why tax compliance, after all, is so high. Institutions that tend to increase tax morale, and thereby increase the social cost of tax evasion, are the government's effectiveness, control of corruption, rule of law, and regulatory quality. ${ }^{25}$ To find an estimate on the governance and credibility of institutions in South and North for the year 2009, we make use of the World Bank's World Governance Indicates (WGI). ${ }^{26}$ The index used reflects perceptions of the quality of public services, the quality of the civil service and the degree of its independence from political pressures, the quality of policy formulation and implementation, and the credibility of the government's commitment to such policies. The index for the period 2006-2015 is 2.26 for North and 0.31 for South, implying that the index is substantially higher for North than South. This indicates that North has a governance structure and institutions that to a substantially larger extent strengthen tax morale than what is the case in South. ${ }^{27}$

In what follows, we will calibrate and simulate the model developed in the previous section to fit North and South. The aim is to pin down the importance of various factors in explaining the differences in the size of the informal economy in South and North. Moreover, the model enables us to quantitatively determine the actual unemployment rates for the regions, accounting also for informal employment. This is carried out with the caveat that, given the simplicity of the model, we consider these calculations as illustrative, without aiming to provide specific guidance in terms of specific policy conclusions regarding these policies in order to punish the informal sector and set taxes.

\subsection{Calibration}

We assume that the year is the basic time unit. Productivity $y$ is normalised to 1 and the real interest rate $r$ is 0.05 . The values of the elasticity of the expected duration of a vacancy with respect to tightness, $\eta$, used in the literature vary widely. For instance, Hall (2005) uses 0.24, while Shimer (2005) uses $0.72 .{ }^{28}$ Petrongolo and Pissarides (2001) in their literature survey consider $[0.5,0.7]$ to be the range of plausible values. We therefore set $\eta$ to 0.5 in both regions. The separation rate is $s=0.08$ (see Millard and Mortensen, 1997). We let the search efficiency parameter be relative low and equal for both regions, $\gamma=0.35$. The tax wedges, $\phi^{F}$, are set to 1.73 and 1.69 in South and North, respectively, consistent with the measures given above from OECD. The expected punishment fees, $p \alpha$ and $p \delta$, are set to 0.0001 , in both regions corresponding to very low detection rates. The employment protection legislation, $\mu$, is set to $\mu_{S}=0.0487$ in South and $\mu_{N}=0.0369$ in North. ${ }^{29}$ We include a match parameter $M^{j}$ in front of the matching function in order to match the differences in unemployment rates between South and North more precisely. The parameters $k_{S}, k_{N}$ and $M_{S}^{j}$ and $M_{N^{\prime}}^{j} j=F, I$, are set to replicate an average observable

\footnotetext{
${ }^{25}$ See Torgler (2011a).

${ }^{26}$ The Worldwide Governance Indicators (WGI) are a research dataset summarising the views on the quality of governance provided by a large number of enterprise, citizen and expert survey respondents in industrial and developing countries. These data are gathered from a number of survey institutes, think tanks, non-governmental organizations, international organizations, and private sector firms. The index averages capturing government effectiveness in a country for the period 2006-2015 is 2.00 in North and 0.74 in South, where the estimates ranges from approximately -2.5 (weak) to 2.5 (strong) governance performance.

${ }^{27}$ The indexes for the rule of law, and regulatory quality shows the same pattern.

${ }^{28}$ See Gertler and Trigari (2009) for a review of values used in other studies.

${ }^{29} \mathrm{http}$ :/ / www.oecd.org/els/emp/oecdindicatorsofemploymentprotection.htm
} 
Table 1: Parameter values

\begin{tabular}{|c|c|c|c|c|c|c|c|c|c|c|c|}
\hline & $y$ & $r$ & $s$ & $\gamma$ & $\eta$ & $k$ & $\phi^{t}$ & $\mu$ & $M^{F}$ & $M^{I}$ & $\kappa$ \\
\hline \hline South & 1 & 0.05 & 0.08 & 0.35 & 0.5 & 0.2 & 1.73 & 0.0487 & 2.55 & 2.2 & 1.1976 \\
\hline North & 1 & 0.05 & 0.08 & 0.35 & 0.5 & 0.4 & 1.69 & 0.0369 & 2.4 & 1.8 & 1.5248 \\
\hline
\end{tabular}

Table 2: Calibrations for North and South

\begin{tabular}{|c|c|c|c|c|c|c|c|c|c|c|}
\hline & \multicolumn{3}{|l|}{ Data } & \multicolumn{1}{l|}{ Calibration } \\
\hline & $u^{0}$ & $\rho$ & $u$ & $\kappa$ & $\kappa$ & $\phi^{F}$ & $\mu$ & $u^{0}$ & $\rho$ & $u$ \\
\hline \hline South & 14.2 & 13.6 & - & - & 1.1976 & 1.73 & 0.0487 & 14.20 & 12.35 & 2.11 \\
\hline North & 6.2 & 3 & - & - & 1.5248 & 1.68 & 0.0369 & 6.2 & 3 & 3.31 \\
\hline
\end{tabular}

unemployment rate for the years 2006 to 2015 of $u_{S}^{o}=14.2 \%$ in South and $u_{N}^{o}=6.2 \%$ in North, and the fraction of employed workers in the informal sector relative to all employed workers in South and North given by $\rho_{S}=13.6 \%$ and $\rho_{N}=3 \%$ and the average duration of unemployment of 1.1 years in South and 0.6 years in North. This gives $k_{S}=0.2, M_{S}^{F}=2.55$ and $M_{S}^{I}=2.2$ for South, and $k_{N}=0.4$ and $M_{N}^{F}=2.4$ and $M_{N}^{I}=1.8$ for North. The parameters are presented in Table 1.

The concealment costs for South and North are set to be, $\kappa_{S}=1.1976$ for South and $\kappa_{N}=1.525$ in North. This allows us to match precisely the observable unemployment rates in the two European regions as well as the fraction of informal sector workers in North whereas the calibrated value for the fraction of informal sector workers in South falls a bit short of the measured value and becomes $\rho_{S}=12.35 \%$. It is clear that concealment costs in North need to be significantly larger than in South in order to match the observed differences in the fraction of employed workers in the informal sector to all employed across the regions. The difference in the concealment cost parameters for North and South is, however, fully consistent with the data, although it is not possible to derive an exact value for the concealment costs from the data, as is possible for the tax wedge. The actual unemployment rates are residually determined in the model and are relative low numbers for both South and North, namely $u_{S}=2.12$ and $u_{N}=3.31$. The actual values derived from data and the model values are summarised in table 2 .

\subsection{Impact of policy reforms}

This paper has set up a model in order to evaluate how important concealment costs, taxes as well as employment protection legislation are when comparing the share of informal sector workers in northern and southern European countries. As the tax wedge is similar in North and South, differences in this policy instrument cannot explain the observed difference in the size of the informal sector in terms of fraction of employed workers in informal sector employment. Employment protection and concealment costs, however, differ across regions and can potentially explain the differences we observe across the regions. We will in this section consider the impact changes in concealment costs and employment protection legislation to examine how they differ for the two regions. We also consider the impact of these policies on actual unemployment, where the model delivered more ambiguous results.

Considering Figure 1 and 2 we observe the following. When concealment costs increase in South, there is a sharp decrease in the share of informal sector workers in South, whereas in North an increase in concealment costs would reduce the informal sector from an already low level to something even smaller. Hence, an increase in concealment 
Figure 1: Impact of Concealment Costs, South
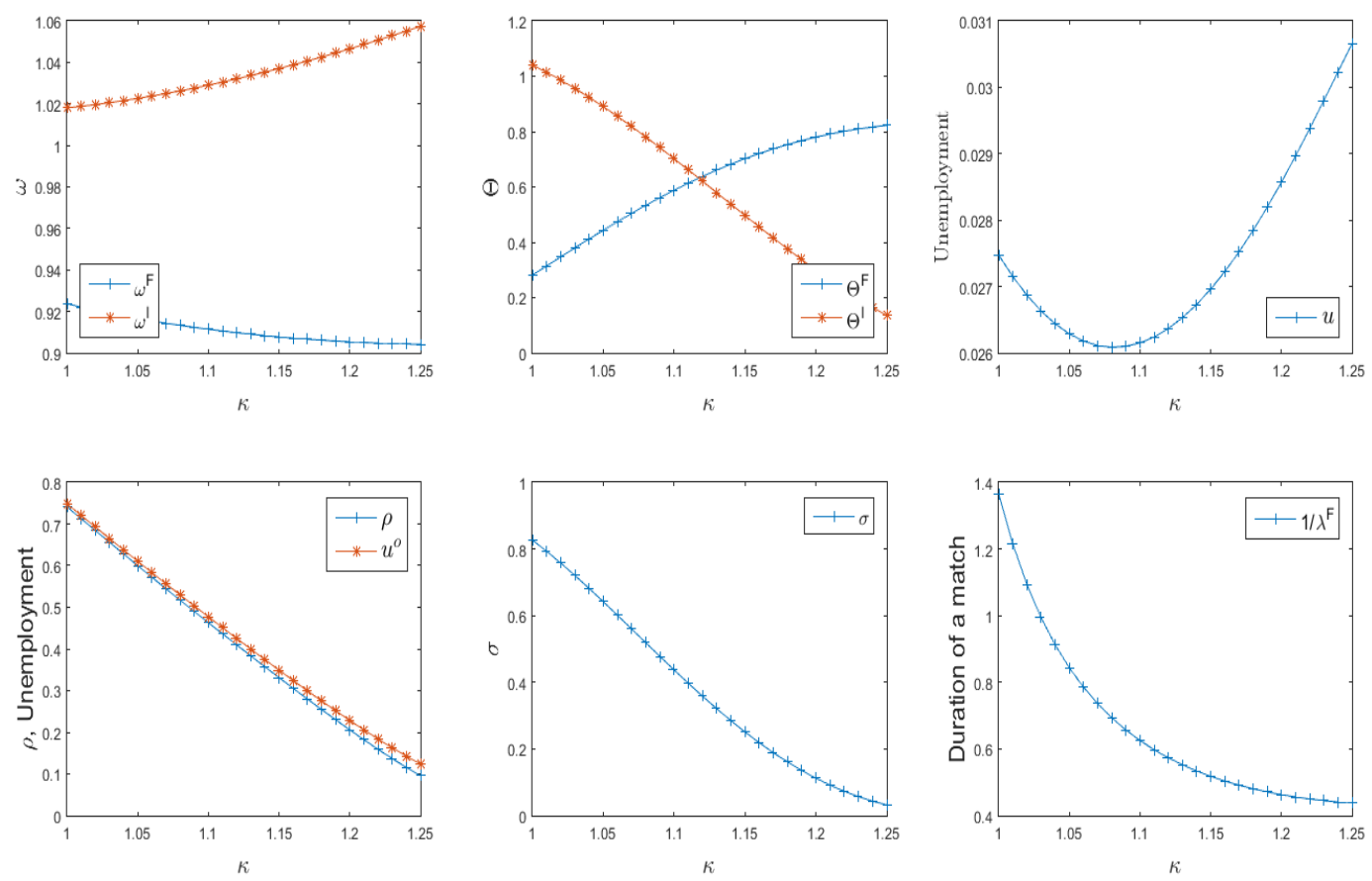

costs will have a huge impact on the informal sector in both regions. ${ }^{30}$ The observable unemployment rate also falls in both regions, the impact again being stronger in South than in North.

Consistent with Proposition 2 the impact on actual unemployment is negative as long as the wedge between the informal sector and the formal sector is below $\psi^{*}>1$, which corresponds to when $\sigma=0.5$, where search is equal in the informal and the formal sector (see the graph representing unemployment and the graph for $\sigma$ in Figure 1 and 2). When search into the informal sector is below a half, $\sigma=0.5$, then any additional unit of search for jobs into the formal sector is less efficient in terms of job matching than it would have been if instead the worker had searched for a job into the informal sector. Concequently, actual unemployment increases with concealment costs. This lower bound of unemployment corresponds to higher concealment costs in South than in North as the calibration of the economy in South is consistent with a lower concealment costs level.

In Figure 3 and 4, we consider the change caused by employment protection legislation. We notice that the share of informal sector workers increases more in South than in North when $\mu$ increases. Examining the graph representing unemployment and the graph for $\sigma$ in Figure 3 and 4, we again have that when search into the informal sector becomes below $\sigma=0.5$, then any additional unit of search into the formal sector becomes less efficient than if the same amount of search would have been conducted in the informal sector, whereby actual unemployment increases. The lowest reachable unemployment rate in North corresponds to higher employment protection legislation than it does in South as the economy in South is calibrated to a higher employment protection legislation level. 
Figure 2: Impact of Concealment Costs, North
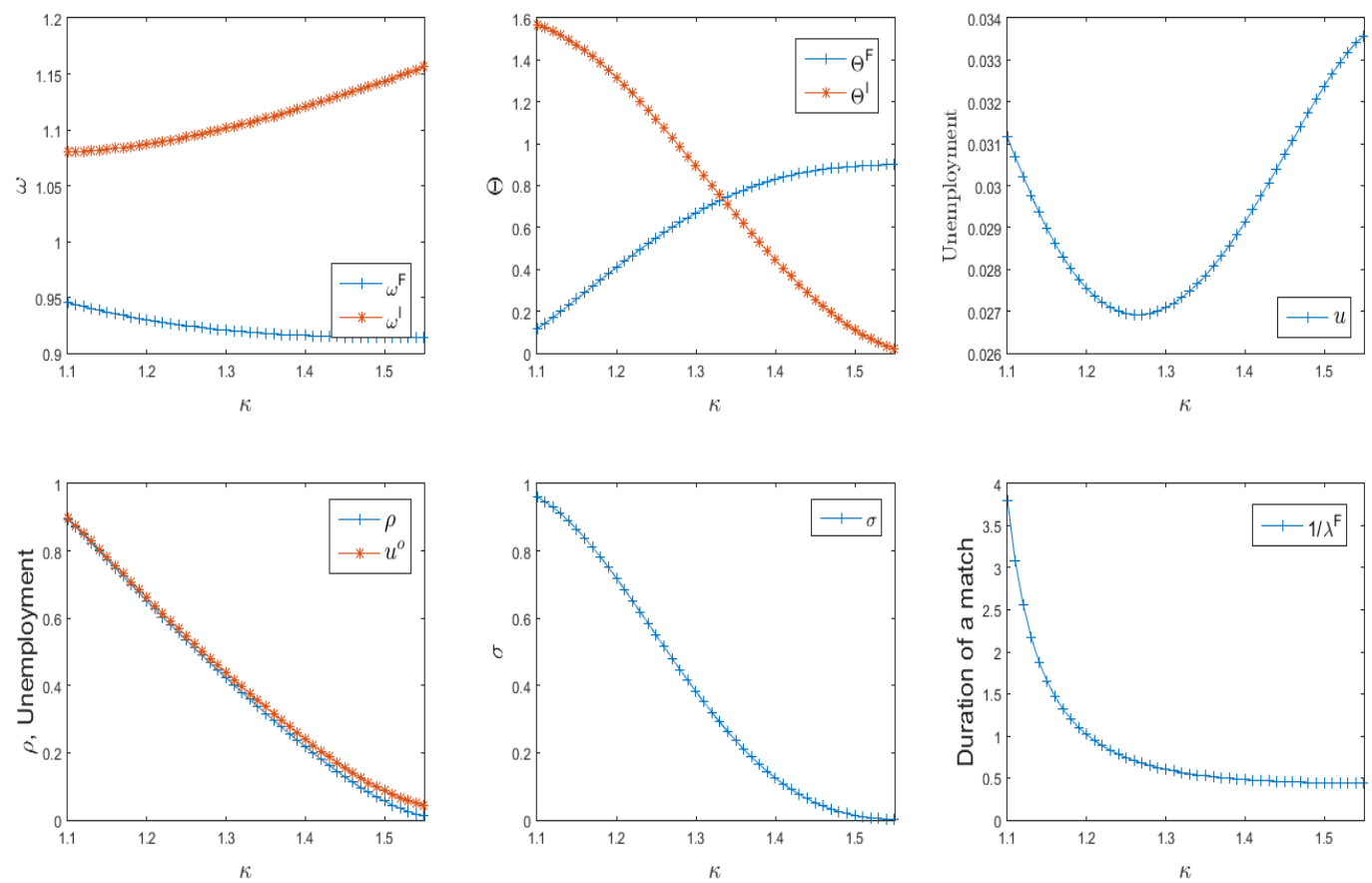

Figure 3: Impact of Employment Protection Legislation, South
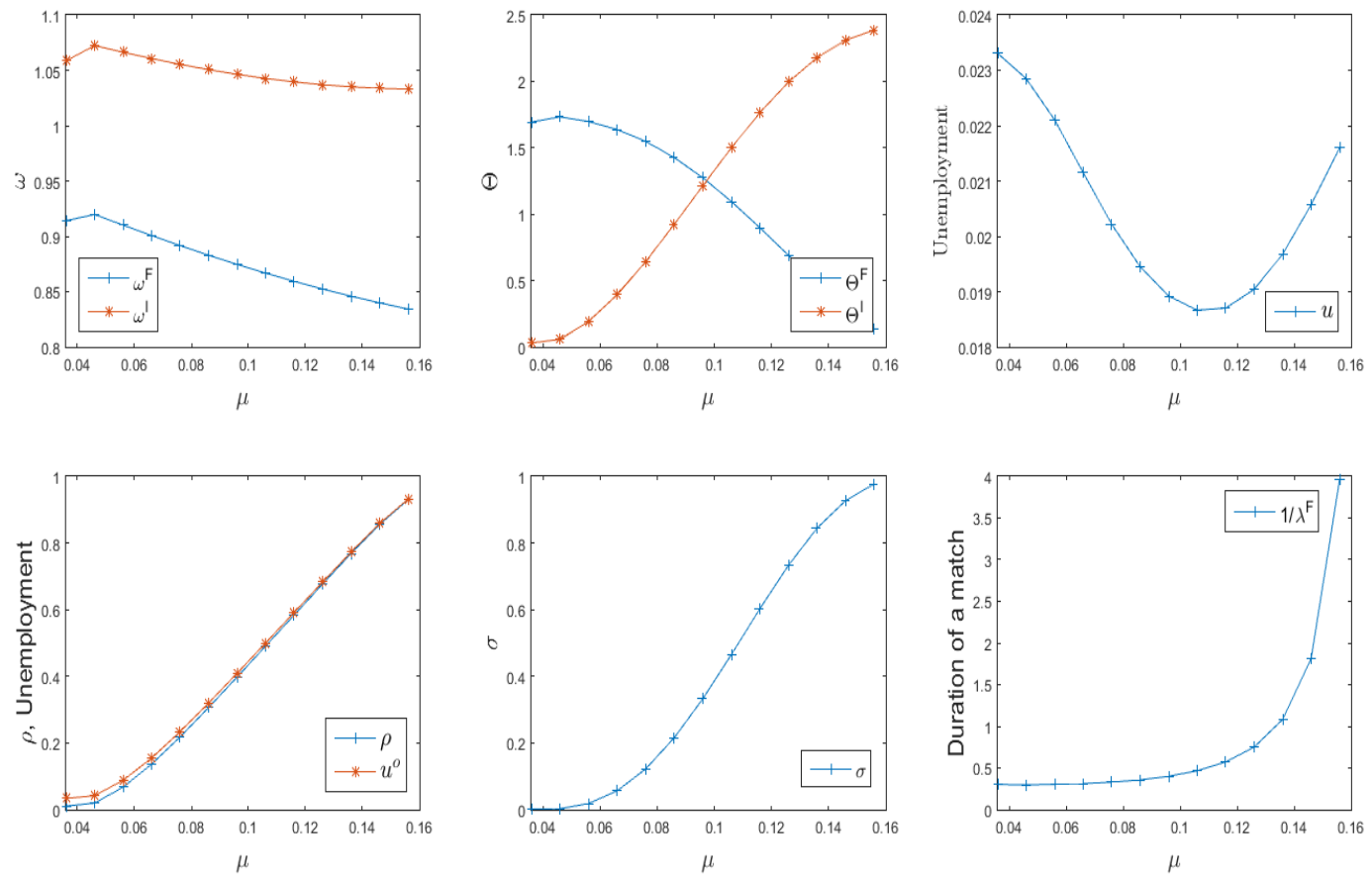
Figure 4: Impact of Employment Protection Legislation, North
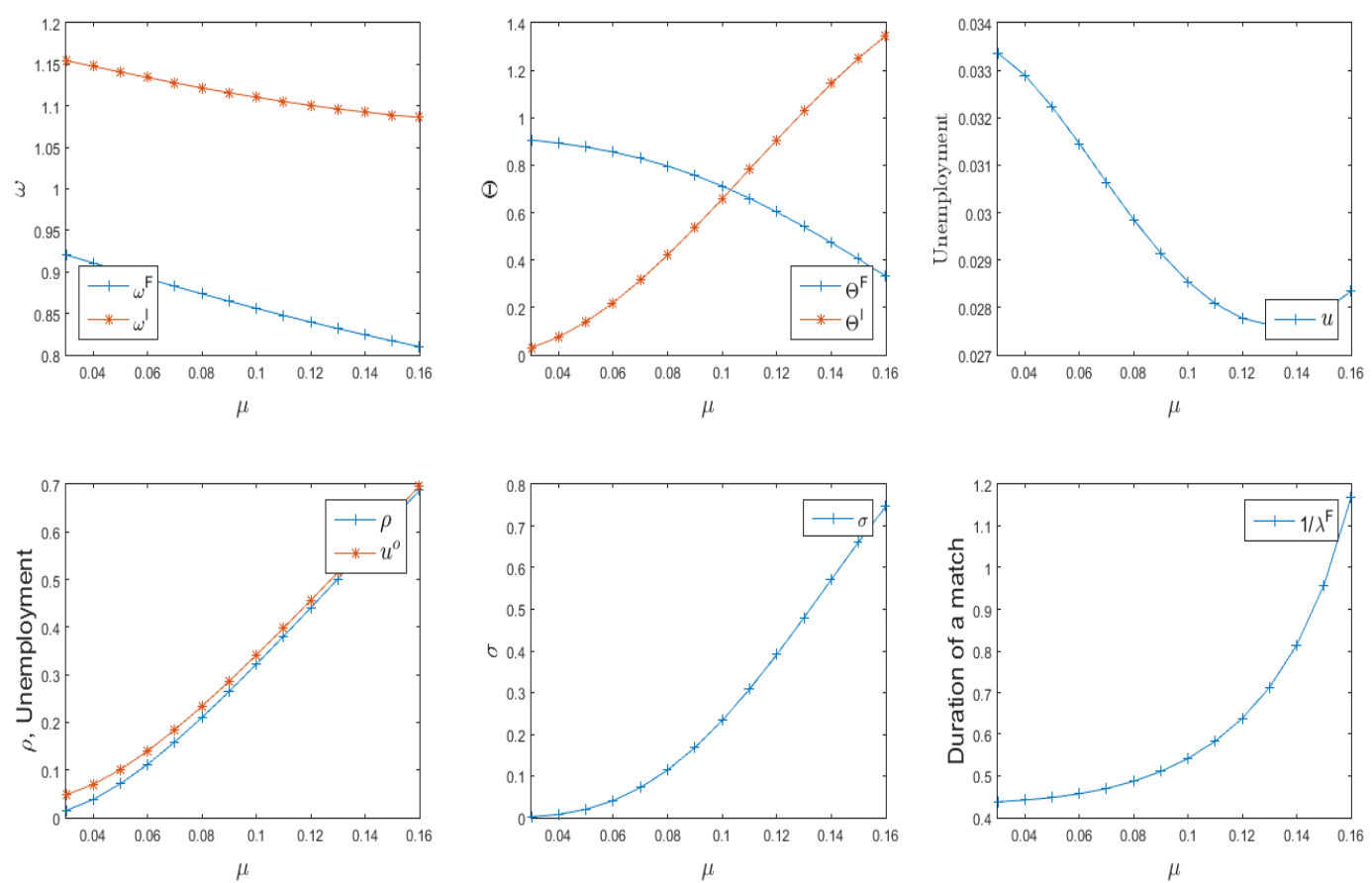

\subsection{Counterfactuals}

The previous sections confirmed that higher concealment costs or lower employment protection legislation reduces the share of informal sector employment. We did not consider the impact of lower taxes as the tax wedges are very similar in North and in South and different tax levels are therefore not the explanation behind the differences in the sizes of the informal sector in South and in North.

In this section we conduct two experiments. First, in the southern part of Europe where the share of informal sector employment is more than four times higher than in the northern part of Europe, we ask how much concealment costs need to increase in South in order to obtain the same size of the informal sector as in North. We then evaluate the impact on observable and actual unemployment. Next, we perform a similar experiment with the costs of employment protection legislation.

The result we obtain is that concealment costs have to increase by 3.8 percent to $\kappa_{S}^{\prime}=1.236$ in order for South to obtain the same share of informal sector workers as in North, $\left.\rho_{S}\right|_{\mathcal{K}_{S}^{\prime}=1.236}=\rho_{N}=3 \%$. This results in an observable unemployment rate in South of $\left.u_{S}^{o}\right|_{\kappa=2.236}=5.2 \%$ and an actual unemployment rate in South given by $\left.u_{S}\right|_{\mathcal{K}_{S}^{\prime}=1.236}=$ $2.27 \%$. Concealment costs do therefore not need to increase all the way up to being at the same level as in North, given the calibrated equilibrium. Hence, although actual unemployment increases, the impact on wages, job

\footnotetext{
${ }^{30}$ This is in line with the result from the field experiment in Denmark by Kleven et al. (2011) who concluded that third-party reporting was a very efficient way to reduce tax evasion. They found that employees almost never evaded taxes, whereas self-employed, where the cost of evasion can be considered to be substantially lower due to the absence of third-party reporting, did. Although, this model does not contain self-employed, it illustrates the potential efficiency of the policy instrument.
} 
creation and search lead only to a long run increase in actualy unemployment of 0.17 percentage points (which in fact is 16 percent).

Next, we consider how much employment protection legislation needs to fall in South for this region to reach the same share of informal sector workers as in North. We here keep concealment costs at the original calibrated level, $\kappa_{S}=1.1976$. We obtain that employment protection legislation has to fall to $\mu_{S}^{\prime}=0.0328$ to obtain

$\left.\rho_{S}\right|_{\mu_{S}^{\prime}=0.0328}=\rho_{N}=3 \%$. In this case, employment protection legislation has to fall by a very large amount and almost become as low as in North in order to reach the goal. The impact on observable unemployment as well as actual unemployment give the following $\left.u_{S}^{o}\right|_{\mu_{S}^{\prime}=0.0328}=4.32 \%$ and $\left.u_{S}\right|_{\mu_{S}^{\prime}=0.0328}=2.68 \%$, which correspond to a larger increase in actual unemployment than when concealment costs increases are used to reduce the informal sector, the impact being 0.57 percentage points or a 27 percent increase.

We therefore observe that higher concealment costs in South would be very efficient if we want to reduce the share of informal sector workers in South to the same level as in North. The most direct and easiest method to use in order to increase concealment costs is likely to be third party reporting, as social norms and corruption may take longer to affect. Reducing employment protection legislation in South would also reduce the informal sector, but the necessary reduction is large and politically this may be much more problematic. The reason is that in North a heavily subsidised unemployment insurance system is pronounced, and employment protection therefore may be less important than in South. A significant reduction of employment protection costs in South, so that the level becomes close to the level in North, may seem socially unacceptable as vulnerable groups of the society potentially are severely negatively affected.

\section{Conclusion}

While existing literature is mainly focused on the direct impact of tax and punishment policy on tax evasion, the aim of this paper was to capture the general equilibrium effects related to the underground economy, taking wage impacts and an endogenous allocation of workers into the formal and informal sector into account. We then examined whether this model could be used as a tool to explain the observed differences between the northern European and the southern European countries.

To this end, we built a general equilibrium model in terms of a search and matching model with an informal sector. We considered the impact of the traditional policy instruments considered in the tax evasion literature, such as changes in the tax- and punishment system as well as changes in the employment protection legislation, on labour market outcomes. Next, we considered the impact of concealment costs, that is, costs related to it being difficult and costly to hide earned income from the tax authorities, on tax evasion. Such costs have recently become important in the tax evasion literature when it comes to explaining observed tax evasion, as traditional policy instruments cannot explain the low amount of tax evasion observed. The model allowed workers to allocate their search for formal and informal sector jobs optimally. Wages were set in wage negotiations between workers and firms and unemployment was an equilibrium outcome. To keep the model simple, we accounted for only a few differences between the formal and the informal sector, the first difference between the formal and the informal sector being that taxes were paid in the former and a fine was paid upon detection in the latter. Informal sector firms also faced costs of concealing their evasion. Finally, we included employment protection legislation costs for formal sector firms.

We found that increased costs of evasion, either through increased audit rates, more extensive sanctions or third party reporting, or even through policies increasing social costs, induced a reallocation of firms and workers towards the formal sector. Corresponding to this, informal sector producer wages increased and formal sector producer wages fell, and more workers became unemployed even though the observable unemployment rate decreased. Thus less formal jobs were created than informal jobs being destroyed. This was a result of the aggregate 
wage pressure increasing due to the reallocation process of workers and firms. Stricter employment protection legislation was found to induce a movement from the formal sector to the informal sector, and the impact on actual unemployment was in this case ambiguous.

Then we calibrated and simulated the model to fit the northern European countries (Denmark, Finland, Norway, and Sweden) denoted North and four south European countries (Greece, Italy, Portugal, and Spain) denoted South. The share of informal sector workers is equal to three percent in North and more than 4 times as high in South, namely 13.6 percent. As the taxation of labour and the probability of being detected is not that different across regions, these policy instruments could not explain the rather large difference in the informal sector share observed in these regions. Therefore, we considered the impact of concealment costs, as there are differences in terms of tax administration procedures between South and North, which indicate that the northern countries make more extensive use of third-party reporting. These results are also in line with the empirical evidence on tax morale and social costs of tax evasion for the regions. Concealment costs could indeed be used to explain the difference in size of the informal sector in South and in North. Finally, OECD numbers for employment protection legislation showed a more severe employment protection legislation in South than in North. The simulations of the model confirmed that the stricter employment protection legislation in Southern Europe could partly be used to explain why more tax evasion is observed in southern than in northern Europe.

\section{References}

[1] Albrecht, J., Navarro, L., \& Vroman, S. (2009). The effects of labour market policies in an economy with an informal sector. The Economic Journal, 119(539), 1105-1129.

[2] Allingham, M. G., \& Sandmo, A. (1972). Income tax evasion: A theoretical analysis. Journal of Public Economics, 1(3-4), 323-338.

[3] Andreoni, J., Erard, B., \& Feinstein, J. (1998). Tax compliance. Journal of Economic Literature, 36(2), 818-860.

[4] Bjørneby, M., Alstadsæter, A., \& Telle, K. (2017). Collaborative Tax Evasion by Employers and Employees: Evidence from a Randomized Field Experiment. Mimeo, Norwegian University of Life Science.

[5] Boeri, T., \& Garibaldi, P. (2002). Shadow activity and unemployment in a depressed labour market. Mimeo.

[6] Bosch, M., \& Esteban-Pretel, J. (2012). Job Creation and Job Destruction in the Presence of Informal Markets. Journal of Development Economics, 98(2), 270-286.

[7] Buehn, A., \& Schneider, F. (2012). Shadow economies around the world: novel insights, accepted knowledge, and new estimates. International Tax and Public Finance, 19.

[8] Cremer, H., \& Gahvari, F. (1993). Tax evasion and optimal commodity taxation. Journal of Public Economics, 50(2), 261-275.

[9] Di Nola, A., Kocharkov, G., \& Visilev A. Envelope Wages, Hidden Production and Labour Productivity, Mimeo, University of Konstanz.

[10] EC (2007), Undeclared Work in the European Union, Special Eurobarometer 284.

[11] EC (2014), Undeclared Work in the European Union, Special Eurobarometer 402.

[12] Feige, E. L. (2016). Reflections on the Meaning and Measurement of Unobserved Economies: What Do We Really Know About the 'Shadow Economy. Journal of Tax Administration. 2(1), 6-40.

[13] Fialová, K., \& Schneider, O. (2011). Labor institutions and their impact on shadow economies in Europe. World Bank, Policy Research Working Paper, 5913. 
[14] Frey, B. S., \& Torgler, B. (2007). Tax morale and conditional cooperation. Journal of Comparative Economics, 35(1), 136-159.

[15] Fugazza, M., \& Jacques, J. F. (2004). Labor market institutions, taxation and the underground economy. Journal of Public Economics, 88(1), 395-418.

[16] Gertler, M., \& Trigari, A. (2009). Unemployment fluctuations with staggered Nash wage bargaining. Journal of political Economy, 117(1), 38-86.

[17] Gordon, R., \& Li, W. (2009). Tax structures in developing countries: Many puzzles and a possible explanation. Journal of Public Economics, 93(7), 855-866.

[18] Günther, I., \& Launov, A. (2012). Informal employment in developing countries: Opportunity or last resort?. Journal of Development Economics. 97(1), 88-98.

[19] Hall, R. E. (2005). Employment fluctuations with equilibrium wage stickiness. American Economic Review, 5065.

[20] Hazans, M. (2011/12). What Explains Prevalence of Informal Employment in European Countries: The Role of Labor Institutions, Governance, Immigrants, and Growth. World Bank Policy Research Working Paper, 5917, Washington DC: World Bank. Available at SSRN: http:/ / ssrn.com/abstract=1972832.

[21] Højsgaard Andersen, L., Hedeager Bentsen, K., Hvidtfeldt, C., Jensen, B., Skaksen, J. R., \& Ebbesen Skov, P. (2017). Danskernes liv med skatter, sort arbejde og gør det selv-arbejde, Copenhagen.

[22] Kleven, H. J., Knudsen, M. B., Kreiner, C. T., Pedersen, S., \& Saez, E. (2011). Unwilling or unable to cheat? Evidence from a tax audit experiment in Denmark. Econometrica, 79(3), 651-692.

[23] Kleven, H. J., Kreiner, C. T., \& Saez E. (2016). Why can modern governments tax so much? An agency model of firms as fiscal intermediaries. Economica, 83(330), 219-246.

[24] Kleven, H. J. (2014). How can Scandinavia tax so much?. Journal of Economic Perspectives, 28, 77-98.

[25] Kolm, A-S., \& Larsen, B. (2003). Social Norm, the Informal Sector, and Unemployment. Finanzarchiv, 59(3), 407-424.

[26] Kolm, A-S., \& Larsen, B. (2006). Wages, unemployment, and the underground economy. Tax Policy and Labor Market Performance. MIT press.

[27] Kolm, A-S., \& Larsen, B. (2016). Informal unemployment and education. IZA: Journal of Labor Economics, 5(8).

[28] Kolm, A. S., \& Nielsen, S. B. (2008). Under-reporting of Income and Labor Market Performance. Journal of Public Economic Theory, 10(2), 195-217.

[29] la Porta, R., \& Shleifer, A. (2014). Informality and development. The Journal of Economic Perspectives, 28(3), 109-126.

[30] Meghir, C., Narita, R., \& Robin, J. M. (2015). Wages and informality in developing countries. The American Economic Review, 105(4), 1509-1546.

[31] Millard, S.P., \& Mortensen, D. T. (1997). The Unemployment and Welfare Effects of Labour Market Policy: A Comparison of the USA and UK. In: Snower D. and G. de la Dehesa, eds., Unemployment Policy: Government Options for the Labour Market. Oxford University Press, Oxford.

[32] Packard, T. G., Koettl, G., \& Montenegro, C. (2012). In from the Shadow: Integrating Europe's Informal Labor. World Bank Publications.

[33] Perry, G. (2007). Informality: Exit and exclusion. World Bank Publications. 
[34] Petrongolo, B., \& Pissarides, C. A. (2001). Looking into the black box: A survey of the matching function, J. Econ. Lit. 39 (2), 390-431.

[35] Pomeranz, D. (2015). No Taxation without Information: Deterrence and Self-Enforcement in the Value Added Tax. American Economic Review, 105(8), 2539-69.

[36] Prado, M. (2011). Government policy in the formal and informal sectors. European Economic Review, 55(8), 1120-1136.

[37] Sandmo, A. (1981). Income tax evasion, labour supply, and the equity-efficiency tradeoff. Journal of Public Economics, 16(3), 265-288.

[38] Schneider, F., Buehn, A., \& Montenegro, C. E. (2010). Shadow economies all over the world. World Bank Policy Research Working Paper 5356.

[39] Shimer, R. (2005) The cyclical behavior of equilibrium unemployment and vacancies. American Economic Review, 25-49.

[40] Srinivasan, T. N. (1973). Tax evasion: A model. Journal of Public Economics, 2(4), 339-346.

[41] Tonin, M. (2011). Minimum wage and tax evasion: Theory and evidence. Journal of Public Economics, 95(11), $1635-1651$.

[42] Torgler, B. (2011a). Tax morale and compliance: review of evidence and case studies for Europe, Background paper for: In from the Shadow: Integration Europe's Informal Labor, Policy Research Working Paper, 5922, World Bank, Washington, DC.

[43] Ulyssea, G. (2010). Regulation of entry, labor market institutions and the informal sector. Journal of Development Economics, 91(1), 87-99.

[44] Van den Berg, G. J., \& Van der Klaauw, B. (2006). Counseling and monitoring of unemployed workers: Theory and evidence from a controlled social experiment. International Economic Review, 47(3), 895-936.

[45] Williams, C.C. (2009). Formal and Informal Employment in Europe: Beyond Dualistic Representations. European Urban and Regional Studies, 16(2), 147-159.

\section{Appendix}

In this Appendix we derive the impact on labour market performance of higher concealment costs, expected tax and punishment rates as well as higher employment protection.

\subsection{Impact of conceilment costs when $\mu=0$ :}

We consider the equilibrium when $\mu=0$, which is given by equation (16), (18) and then equation (17) when $\mu=0$, that is

$$
2(r+s) k\left(\theta^{F}\right)^{\eta}=y-\frac{k \theta^{F}}{(1-\sigma)^{1-\gamma}}
$$


We differentiate the three equations in $\sigma, \theta^{F}, \theta^{I}$ and $\kappa$ to obtain around the equilibrium and for $\psi>1$ :

$$
\begin{gathered}
\frac{d \sigma}{d \kappa}=\frac{\eta\left(y+\frac{(1-\eta)}{\eta} \frac{k \theta^{F}}{(1-\sigma)^{1-\gamma}}\right)}{D}\left(\theta^{F}\right)^{-1} \frac{1}{\psi} \frac{d \psi}{d \kappa}<0, \\
\frac{d \theta^{F}}{d \kappa}=\frac{\frac{(1-\gamma)}{1-\sigma} \frac{k \theta^{F}}{(1-\sigma)^{1-\gamma}}}{-D} \frac{1}{\psi} \frac{d \psi}{d \kappa}>0 \\
\frac{d \theta^{I}}{d \kappa}=\frac{\frac{(1-\gamma)}{\sigma} \frac{k \theta^{I}}{\sigma^{1-\gamma}}}{\eta\left(y+\frac{(1-\eta)}{\eta} \frac{k \theta^{I}}{\sigma^{1-\gamma}}\right)} \theta^{I} \frac{d \sigma}{d \kappa}<0
\end{gathered}
$$

where

$$
D=-\frac{1-\gamma}{\sigma}\left(\left(\frac{1}{1-\sigma}-F\right)\left(y-\frac{k \theta^{F}}{(1-\sigma)^{1-\gamma}}\right) \eta+\frac{k \theta^{F}}{(1-\sigma)^{1-\gamma}}(1-F)\right)\left(\theta^{F}\right)^{-1}<0,
$$

where $F=\frac{\frac{k \theta^{I}}{\sigma^{1-\gamma}}}{\left(\eta\left(y-\frac{k \theta^{I}}{\sigma^{1-\gamma}}\right)+\frac{k \theta^{I}}{\sigma^{1-\gamma}}\right)}<1$ and as $\left(y-\frac{k \theta^{F}}{(1-\sigma)^{1-\gamma}}\right)>0$ from equation (17). The impact on unemployment is then:

$$
\frac{d u}{d \kappa}=\frac{-s}{\left(s+\lambda^{F}+\lambda^{I}\right)^{2}}\left(\frac{d \lambda^{F}}{d \kappa}+\frac{d \lambda^{I}}{d \kappa}\right)
$$

Unemployment therefore increases if $\left(\frac{d \lambda^{F}}{d \kappa}+\frac{d \lambda^{I}}{d \kappa}\right)<0$. We derive this sum to be

$\frac{d \lambda^{F}}{d \kappa}+\frac{d \lambda^{I}}{d \kappa}=\sigma_{i}^{\gamma}\left(\theta^{I}\right)^{(1-\eta)} \frac{1}{\sigma}\left(\left(1-\frac{\left(\theta^{I}\right)^{\eta}}{\left(\theta^{F}\right)^{\eta}} \frac{1}{\psi}\right) \gamma \frac{d \sigma}{d \kappa}-\frac{(1-\gamma)(1-\eta)}{-D \psi^{2} \theta^{F}} \frac{k \theta^{I}}{\sigma^{1-\gamma}}\left(\frac{\left(\psi y+\frac{(1-\eta)}{\eta} \frac{k \theta^{I}}{\sigma^{1-\gamma}}\right)}{\left(y+\frac{(1-\eta)}{\eta} \frac{k \theta^{I}}{\sigma^{1-\gamma}}\right)}-\frac{\left(\theta^{I}\right)^{\eta}}{\left(\theta^{F}\right)^{\eta}} \frac{1}{\psi}\right) \frac{d \psi}{d \kappa}\right) \lesseqgtr 0$

for $\psi \gtreqless 1$. And hence unemployment increases (decreases/unaffected) with concealment costs, $\kappa$ when for $\psi \gtreqless 1$.

The impact on observable unemployment is

$$
\frac{d u^{o}}{d \kappa}=\frac{\frac{d \lambda^{I}}{d \kappa}\left(\lambda^{F}+\lambda^{I}\right)-s\left(\frac{d \lambda^{F}}{d \kappa}\right)}{\left(s+\lambda^{F}+\lambda^{I}\right)^{2}}<0
$$

as

$$
\begin{gathered}
\frac{d \lambda^{F}}{d \kappa}=\left(1-\sigma_{i}\right)^{\gamma}\left(\theta^{F}\right)^{(1-\eta)}\left(-\frac{\gamma}{1-\sigma} \frac{d \sigma}{d \kappa}+\frac{(1-\eta)}{\theta^{F}} \frac{d \theta^{F}}{d \kappa}\right)>0 \\
\frac{d \lambda^{I}}{d \kappa}=\sigma_{i}^{\gamma}\left(\theta^{I}\right)^{(1-\eta)}\left(\frac{\gamma}{\sigma} \frac{d \sigma}{d \kappa}+\frac{(1-\eta)}{\theta^{I}} \frac{d \theta^{I}}{d \kappa}\right)<0 .
\end{gathered}
$$


The impact on relative employment is:

$$
\frac{d \rho}{d \kappa}=\frac{\frac{d \lambda^{I}}{d \kappa}\left(\lambda^{F}\right)-\lambda^{I}\left(\frac{d \lambda^{F}}{d \kappa}\right)}{\left(\lambda^{F}+\lambda^{I}\right)^{2}}<0
$$

\subsection{Impact of expected tax and punishment rates when $\mu=0$ :}

We again consider the equilibrium when $\mu=0$, which is given by equation (16), (20) and (18).

We differentiate the three equations in $\sigma, \theta^{F}, \theta^{I}$ and $l=\frac{1+p \alpha}{1-p \delta}, \frac{1}{\phi^{F}}$, to obtain around the equilibrium and for $\psi>1$ :

$$
\begin{gathered}
\frac{d \sigma}{d l}=\frac{\eta\left(y+\frac{(1-\eta)}{\eta} \frac{k \theta^{F}}{(1-\sigma)^{1-\gamma}}\right)}{D}\left(\theta^{F}\right)^{-1} \frac{1}{\psi} \frac{d \psi}{d l}<0, \\
\frac{d \theta^{F}}{d l}=\frac{\frac{(1-\gamma)}{1-\sigma} \frac{k \theta^{F}}{(1-\sigma)^{1-\gamma}}}{-D} \frac{1}{\psi} \frac{d \psi}{d l}>0, \\
\frac{d \theta^{I}}{d l}=\frac{\frac{(1-\gamma)}{\sigma} \frac{k \theta^{I}}{\sigma^{1-\gamma}}}{\eta\left(y+\frac{(1-\eta)}{\eta} \frac{k \theta^{I}}{\sigma^{1-\gamma}}\right)} \theta^{I} \frac{d \sigma}{d l}<0,
\end{gathered}
$$

where

$$
D=-\frac{1-\gamma}{\sigma}\left(\left(\frac{1}{1-\sigma}-F\right)\left(y-\frac{k \theta^{F}}{(1-\sigma)^{1-\gamma}}\right) \eta+\frac{k \theta^{F}}{(1-\sigma)^{1-\gamma}}(1-F)\right)\left(\theta^{F}\right)^{-1}<0,
$$

where $F=\frac{\frac{k \theta^{I}}{\sigma^{1-\gamma}}}{\left(\eta\left(y-\frac{k \theta^{I}}{\sigma^{1-\gamma}}\right)+\frac{k \theta^{I}}{\sigma^{1-\gamma}}\right)}<1$ and as $\left(y-\frac{k \theta^{F}}{(1-\sigma)^{1-\gamma}}\right)>0$ from equation (17). The impact on unemployment is then:

$$
\frac{d u}{d l}=\frac{-s}{\left(s+\lambda^{F}+\lambda^{I}\right)^{2}}\left(\frac{d \lambda^{F}}{d l}+\frac{d \lambda^{I}}{d l}\right) \text {. }
$$

Unemployment therefore increases if $\left(\frac{d \lambda^{F}}{d l}+\frac{d \lambda^{I}}{d l}\right)<0$. We derive this sum to be

$\frac{d \lambda^{F}}{d l}+\frac{d \lambda^{I}}{d l}=\frac{\left(\theta^{I}\right)^{1-\eta}}{\sigma^{1-\gamma}}\left(\left(1-\frac{\left(\theta^{I}\right)^{\eta}}{\left(\theta^{F}\right)^{\eta}} \frac{1}{\psi}\right) \gamma \frac{d \sigma}{d l}-\frac{(1-\gamma)(1-\eta)}{-D \psi^{2} \theta^{F}} \frac{k \theta^{I}}{\sigma^{1-\gamma}}\left(\frac{\left(\psi y+\frac{(1-\eta)}{\eta} \frac{k \theta^{I}}{\sigma^{1-\gamma}}\right)}{\left(y+\frac{(1-\eta)}{\eta} \frac{k \theta^{I}}{\sigma^{1-\gamma}}\right)}-\frac{\left(\theta^{I}\right)^{\eta}}{\left(\theta^{F}\right)^{\eta}} \frac{1}{\psi}\right) \frac{d \psi}{d l}\right) \lesseqgtr 0$,

for $\psi \gtreqless 1$. And hence unemployment increases with expected auditing $l=\frac{1+p \alpha}{1-p \delta}$ and punishment rates and decreases with taxes, $l=1 / \phi^{F}$, when $\psi \gtreqless 1$.

The impact on observable unemployment is then

$$
\frac{d u^{o}}{d l}=\frac{\frac{d \lambda^{I}}{d l}\left(\lambda^{F}+\lambda^{I}\right)-s\left(\frac{d \lambda^{F}}{d l}\right)}{\left(s+\lambda^{F}+\lambda^{I}\right)^{2}}<0,
$$




$$
\begin{gathered}
\frac{d \lambda^{F}}{d l}=\left(1-\sigma_{i}\right)^{\gamma}\left(\theta^{F}\right)^{(1-\eta)}\left(-\frac{\gamma}{1-\sigma} \frac{d \sigma}{d l}+\frac{(1-\eta)}{\theta^{F}} \frac{d \theta^{F}}{d l}\right)>0 \\
\frac{d \lambda^{I}}{d l}=\sigma_{i}^{\gamma}\left(\theta^{I}\right)^{(1-\eta)}\left(\frac{\gamma}{\sigma} \frac{d \sigma}{d l}+\frac{(1-\eta)}{\theta^{I}} \frac{d \theta^{I}}{d l}\right)<0 .
\end{gathered}
$$

The impact on relative employment is

$$
\frac{d \rho}{d l}=\frac{\frac{d \lambda^{I}}{d l}\left(\lambda^{F}\right)-\lambda^{I}\left(\frac{d \lambda^{F}}{d l}\right)}{\left(\lambda^{F}+\lambda^{I}\right)^{2}}<0
$$

\subsection{Higher Employment protection, higher $\mu$.}

We differentiate equation (16) - (18) with respect to $\sigma, \theta^{F}, \theta^{I}$ and $\mu$ to obtain around the equilibrium:

$$
\begin{gathered}
\frac{d \sigma}{d \mu}=\frac{1}{-D}\left(\theta^{F}\right)^{-1}>0, \\
\frac{d \theta^{F}}{d \mu}=\frac{\frac{(1-\gamma)}{\sigma}\left(\frac{1}{(1-\sigma)}-\frac{\frac{k \theta^{I}}{\sigma^{1-\gamma}}}{\eta\left(y+\frac{(1-\eta)}{\eta} \frac{k I^{I}}{\sigma^{1-\gamma}}\right)}\right)}{D}<0, \\
\frac{d \theta^{I}}{d \mu}=\frac{\frac{(1-\gamma)}{\sigma} \frac{k \theta^{I}}{\sigma^{1-\gamma}}}{\eta\left(y+\frac{(1-\eta)}{\eta} \frac{k \theta^{I}}{\sigma^{1-\gamma}}\right)} \theta^{I} \frac{d \sigma}{d \kappa}>0,
\end{gathered}
$$

where

$$
D=-\frac{1-\gamma}{\sigma}\left(\left(\frac{1}{1-\sigma}-F\right)\left(y-\mu-\frac{k \theta^{F}}{(1-\sigma)^{1-\gamma}}\right) \eta+\frac{k \theta^{F}}{(1-\sigma)^{1-\gamma}}(1-F)\right)\left(\theta^{F}\right)^{-1}<0,
$$

where $F=\frac{\frac{k \theta^{I}}{\sigma^{1-\gamma}}}{\left(\eta\left(y-\frac{k \theta^{I}}{\sigma^{1-\gamma}}\right)+\frac{k \theta^{I}}{\sigma^{1-\gamma}}\right)}<1$ and as $\left(y-\mu-\frac{k \theta^{F}}{(1-\sigma)^{1-\gamma}}\right)>0$ from equation (17). The impact on unemployment is then:

$$
\frac{d u}{d \mu}=\frac{-s}{\left(s+\lambda^{F}+\lambda^{I}\right)^{2}}\left(\frac{d \lambda^{F}}{d \mu}+\frac{d \lambda^{I}}{d \mu}\right) .
$$

The impact on unemployment therefore has the opposite sign of $\left(\frac{d \lambda^{F}}{d \mu}+\frac{d \lambda^{I}}{d \mu}\right)$ where

$\frac{d \lambda^{F}}{d \mu}+\frac{d \lambda^{I}}{d \mu}=\frac{1}{-D}\left(\theta^{F}\right)^{-1} \sigma_{i}^{\gamma-1}\left(\theta^{I}\right)^{(1-\eta)}\left((\gamma+(1-\eta)(1-\gamma) F)\left(1-\frac{1}{\psi} \frac{\left(\theta^{I}\right)^{\eta}}{\left(\theta^{F}\right)^{\eta}}\right)-\frac{1}{\psi} \frac{\left(\theta^{I}\right)^{\eta}}{\left(\theta^{F}\right)^{\eta}} \frac{(1-\eta)(1-\gamma)}{\sigma}(1-F)\right)$

where the sign is negative for $\psi \leq 1$. The impact on observable unemployment is

$$
\frac{d u^{o}}{d \mu}=\frac{\frac{d \lambda^{I}}{d \mu}\left(\lambda^{F}+\lambda^{I}\right)-s\left(\frac{d \lambda^{F}}{d \mu}\right)}{\left(s+\lambda^{F}+\lambda^{I}\right)^{2}}>0
$$




$$
\begin{gathered}
\frac{d \lambda^{F}}{d \mu}=\left(1-\sigma_{i}\right)^{\gamma}\left(\theta^{F}\right)^{(1-\eta)}\left(-\frac{\gamma}{1-\sigma} \frac{d \sigma}{d \mu}+\frac{(1-\eta)}{\theta^{F}} \frac{d \theta^{F}}{d \mu}\right)<0 \\
\frac{d \lambda^{I}}{d \mu}=\sigma_{i}^{\gamma}\left(\theta^{I}\right)^{(1-\eta)}\left(\frac{\gamma}{\sigma} \frac{d \sigma}{d \mu}+\frac{(1-\eta)}{\theta^{I}} \frac{d \theta^{I}}{d \mu}\right)>0 .
\end{gathered}
$$

The impact on relative employment is

$$
\frac{d \rho}{d \mu}=\frac{\frac{d \lambda^{I}}{d \mu}\left(\lambda^{F}\right)-\lambda^{I}\left(\frac{d \lambda^{F}}{d \mu}\right)}{\left(\lambda^{F}+\lambda^{I}\right)^{2}}>0
$$

